\title{
Numerical Analysis of the Influence of Geometry on a Large Scale Onshore Oscillating Water Column Device with Associated Seabed Ramp
}

\author{
Max Letzow ${ }^{1}$, Giulio Lorenzini ${ }^{2 *}$, Dante Vinícius Eloy Barbosa ${ }^{3}$, Ricardo Gabriel Hübner ${ }^{1}$, Luiz Alberto Oliveira \\ Rocha $^{3,4}$, Mateus das Neves Gomes ${ }^{5,6}$, Liércio André Isoldi ${ }^{1,5}$, Elizaldo Domingues dos Santos ${ }^{1,5}$ \\ ${ }^{1}$ Graduate Program in Ocean Engineering, Federal University of Rio Grande - FURG, Itália Av., km 8, Rio Grande 96201-900, \\ RS, Brazil \\ ${ }^{2}$ Dipartimento di Ingegneria e Architettura, Università degli Studi di Parma, Parco Area delle Scienze 181/A, Parma 43124, \\ Italy \\ ${ }^{3}$ Graduate Program in Mechanical Engineering, Federal University of Rio Grande do Sul - UFRGS, Sarmento Leite St., 425, \\ Porto Alegre 90050-170, RS, Brazil \\ ${ }^{4}$ Graduate Program in Mechanical Engineering, University of Vale do Rio dos Sinos - UNISINOS, Unisinos Av., 950, São \\ Leopoldo 93022-750, RS, Brazil \\ ${ }^{5}$ Graduate Program in Computational Modeling, Federal University of Rio Grande - FURG, Itália Av., km 8, Rio Grande \\ 96201-900, RS, Brazil \\ ${ }^{6}$ Graduate Program in Science, Technology, and Society, Federal Institute of Paraná - IFPR, Antônio Carlos Rodrigues Av., \\ 453, Paranaguá 83215-750, PR, Brazil
}

Corresponding Author Email: giulio.lorenzini@unipr.it

https://doi.org/10.18280/ijdne.150613

Received: 2 July 2020

Accepted: 7 October 2020

\section{Keywords:}

available power, Constructal Design, numerical simulation, $O W C$, wave energy

\begin{abstract}
The current study aims to perform a geometrical investigation of an onshore Oscillating Water Column (OWC) on a large scale. The Constructal Design method is employed, aiming to maximize its available power. The OWC is subjected to two constraints (areas of the chamber and ramp below the chamber); and three degrees of freedom: height/length ratio of the chamber $\left(H_{l} / L_{1}\right)$, height/length ratio of the ramp $\left(H_{2} / L_{2}\right)$, and submersion of the frontal wall of the chamber $\left(H_{3}\right)$. A laminar, unsteady, incompressible, and two-phase flow was adopted, solving conservation equations of mass, momentum, and transport of water-air volume fraction using Finite Volume Method (FVM) and Volume of Fluid (VOF) model. The global optimal geometry led to a twice maximized available power $37.3 \%$ higher than the best case without the seabed ramp below the chamber and seven times better than the worst case. Concerning the sensibility of geometry, results indicated that the chamber geometry, given by ratio $H_{l} / L_{l}$, over the available power $(P)$ was strongly affected by the ramp ratio $H_{2} / L_{2}$. Moreover, the behavior of the effect of $H_{2} / L_{2}$ over the once maximized available power $\left(P_{m}\right)$ and corresponding optimal shape of the chamber, $\left(H_{l} / L_{l}\right)_{\mathrm{o}}$, changed dramatically for two different magnitudes of $\mathrm{H}_{3}$ investigated.
\end{abstract}

\section{INTRODUCTION}

Ocean waves have been considered an important study object in the renewable energy field [1-4]. It is estimated that their potential achieves 2 TW near the continental areas [5]. Because of that, studies related to Ocean Wave Energy Converters (OWEC) have gotten space in literature, and several main operational principles have been investigated [6$11]$.

One of the most promising operational principles is the Oscillating Water Column (OWC). The device has simple technology, and it is in an advanced stage to use on a commercial scale. The main operational principle harnesses the oscillating seawater movement due to the passage of waves to push/pull airflow outside/inside a hydro-pneumatic chamber to convert pneumatic power into electricity. Several important prototypes have been developed as those built-in Tofteshallen, Norway (500 kW); Sakata, Japan (60 kW); Pico, Portugal (400 kW); Islay island, Scotland (500 kW), Mutriku,
Spain (296 kW), Lewis island, Scotland (4.0 MW) [7, 12-17]. It is worth mentioning that several detailed information about building large-scale prototypes, some policies, and important observations about the design can be seen in Refs. [12-17]. Even though the OWC seems to be very promising, it still is in the development stage. One important and desired contribution is the reduction of capital costs of the converters regarding the power generated. Therefore, the knowledge about the influence of design over the device performance is also an important subject to improve the power generated in the devices.

In this sense, several efforts have been performed into experimental and numerical frameworks to improve the physical comprehension of the device's flow and improve the device power take-off (PTO). Into the experimental framework, Dizadji and Sajadian [18] investigated the geometry of the chamber of OWC inserted in a channel of 16.0 $\times 0.7 \times 0.5 \mathrm{~m}$ of dimensions, i.e., a laboratory scale. Two different configurations, with an inclined and standard frontal 
plate of the chamber compared with the main flow direction, were investigated. The authors observed that the device efficiency is highly dependent on the chamber geometry and properties of the incoming water wave.

Mahnamfar and Altunkaynak [19] carried out twenty experimental sets in a wave tank with a length of $15 \mathrm{~m}$. They evaluated five-wave series conditions and four entrance areas of the chambers to maximize the differential pressure in the system. This study found an optimal geometric configuration for all wave series conditions with an opening height of 0.51 $\mathrm{m}$. The best wave series conditions had a height of $23.37 \mathrm{~cm}$, a period of $1.42 \mathrm{~s}$, and a length of $280 \mathrm{~cm}$. Although it was found an optimal case, it is essential to mention that other studied cases seem to be affected by wave series conditions.

Viviano et al. [20] conducted experiments in large-scale OWC devices (nearly 1:5-1:9) in Hannover, Germany. More precisely, in the Grosse Wellenkanal (GWK) facility. The influence of two parameters was investigated over the reflection and loading of an OWC: the water depth and the orifice that mimics the Power Take-Off (PTO). The authors concluded that the OWC structure could reduce the wave reflection, and it can be integrated into vertical wall breakwaters, replacing other low reflection alternatives. Moreover, it was noticed that the installation of OWC also could be interesting in low energy seas.

Later, Mahnamfar and Altunkaynak [21] compared a numerical OWC model with a physical experimental one concerning the power improvement due to the chamber's geometric aspects (length, width, and the angle of the frontal plate). The comparison between numerical and physical models has considered the Nash-Sutcliffe coefficient of efficiency (NSE) and showed a good agreement between the methodologies. The NSE is a coefficient that uses the variance of the numerical time-series divided by the experimental timeseries variance to estimate the accuracy of modeled results [22]. The numerical modeling solved continuity, momentum, and VOF model equations carried out by FLOW 3D software.

The geometric study observed that the chamber front wall inclination also led to a significant gain of power. Dimakopoulos et al. [23] investigated air compressibility effects due to the wave interaction with an OWC. It was employed a simplified model that considers a thermodynamic equation for the air phase and potential flow for the water one. The methodology was validated using large-scale experimental data, where compressibility was evident. The methodology was employed to show the importance of compressible effects in prototype scale devices. More recently, Celik and Altunkaynak [24] investigated the influence of the underwater opening height of the chamber, PTO damping, and wave steepness on the efficiency of conversion experimentally. Results indicated that the optimal damping depends not only on wave characteristics but also on the chamber opening height since it affects the water column surface's behavior in the device.

The numerical modeling has been employed to achieve several relevant recommendations about the design of OWC devices. For instance, Conde and Gato [25] performed numerical simulations of the airflow inside an OWC chamber equipped with two vertical-axis turbines. A horizontal baffleplate was proposed to deflect the air from the turbines, finding that its usage reduces the risk of water-spray towards the turbine. Moreover, this proposed configuration does not seem to disturb the airflow outwards in the turbine. The study also argues that water-spray may be originated because of high tangential velocities that are likely to occur at the air-water interface.

Teixeira et al. [8] proposed an improvement of an OWC using a developed code (Fluinco), which was verified with Fluent code results. This study simulates a large scale device operational principle inside a $10 \mathrm{~m}$ deep wave channel subjected to $1 \mathrm{~m}$ high incident waves with periods from $4 \mathrm{~s}$ to $15 \mathrm{~s}$. Optimal values of front wall depth equal to $2.5 \mathrm{~m}$, and the chamber's length equals to $10 \mathrm{~m}$ were found in terms of pneumatic power. However, chamber height tests indicate little influence over the performance of the device. Recently, Lisboa et al. [26] adopted the general configuration proposed in Teixeira et al. [8] for the numerical analyzes of an OWC installed in a breakwater on the southern Brazilian coast using Fluent software. This study also adds a seabed ramp before the device. The turbine diameter optimization (TDO) regulated the turbine parameters according to incoming wave characteristics. The main focus here was the turbine's investigation, being achieved an optimal performance by using a turbine with a $2.25 \mathrm{~m}$ diameter.

In an innovative numerical study, Elhanafi et al. [27] analyzed the performance of floating-moored offshore OWC considering $2 \mathrm{D}$ and $3 \mathrm{D}$ cases under the numerical procedure. The effect of lip drought, chamber length, and PTO damping on power efficiency were analyzed under a set of incident wave periods. The floating-moored led to a slight improvement in device performance. Bouali and Larbi [28] employed a sequential optimization to maximize the PTO subjected to different geometric configurations and wave conditions. The optimization is sequential, with the optimal configurations memorized at each level of investigation. In the initial step, the first parameter is optimized, considering constant the other parameters. In the second step, the first optimal parameter is considered constant, and the second parameter is optimized. In the third step, the first and second optimal parameters are considered constant, and a third parameter is optimized. This process is repeated until the end of the parameters. Results indicated that the OWC has an optimal operating point that depends on the PTO damping, the thickness, and the height of the front wall and wave conditions.

More recently, Kharati-Koopaee and Fathi-Kelestani [29] investigated the effect of wave steepness at various chamber lengths and bottom slopes over the hydrodynamic efficiency of an OWC device. Results indicated that the longer chambers are the best configurations when the device is subjected to waves with low frequency, while the opposite was noticed for waves of high frequency. Results also indicated that for the shoreline OWC, the bottom slope angle change has a negligible effect on the device efficiency away from the resonance condition. High magnitudes of bottom slope angle led to the highest efficiencies of the device at the resonance condition. It is also worth mentioning that, recently, essential works concerned with investigating OWC devices with dual chambers have been investigated [30]. This device has two chambers placed in the direction of the incoming wave. Each chamber has its PTO system.

Despite several significant contributions, the employment of Constructal Design for geometrical evaluation of a largescale onshore OWC device with a seabed ramp below the device chamber has not been investigated in the literature. Observing that many studies applied a numerical approach to evaluate OWEC devices, the present study proposes a numerical investigation to maximize the available power of an Oscillating Water Column (OWC) using the Constructal 
Design method [31-35]. An important observation is that Constructal Design is not an optimization method but a method based on the Constructal Law. This thermodynamic law is a first principle and states that for any finite-size flow system to persist in time (to live), its design must evolve freely along the time to facilitate access to its internal currents [3135]. The ease of access to the current work's internal currents is represented by the maximization of the available power in the OWC device.

It is worth mentioning that the investigation is not restricted to found an optimal configuration but to evaluate the effect of the aspect ratios of the chamber and ramp for two different depths of a frontal plate over the performance indicator. The method also indicates the interaction among different degrees of freedom, i.e., how the variation of one degree of freedom (DOF) affects the sensibility of other DOFs. To the best of the authors' knowledge, this kind of analysis was not previously performed in the literature, mainly for OWEC on a large scale.

In this way, it is investigated chamber geometrical arrange combined with a seabed ramp's insertion below it. Therefore, two constraints and three DOFs are applied at the OWC and seabed ramp system, and an exhaustive search technique tracks optimized geometric configuration. It is also considered an OWC without the lower ramp as a reference case to compare the effect of ramp usage. The incident wave characteristics and dimensions of the wave channel follow the values proposed in Martins et al. [9] and Barbosa et al. [10], which represent the conditions found on the south coast of Brazil [4].

\section{MATHEMATICAL MODEL}

Commercial code Fluent is used for present computational modeling. It solves the governing equations with boundary and initial conditions applying Finite Volume Method (FVM) discretization [36, 37] and Volume of Fluid (VOF) model [38] for the treatment of water-air two-phase flow. The VOF considers a volume fraction $\alpha(0 \leq \alpha \leq 1.0)$ that determines fluids fraction at each elementary control volume in the domain. Continuity, momentum, and volume fraction equations are used to model the laminar, incompressible, unsteady water-air mixture flow, as given by [38, 39]:

$$
\begin{gathered}
\frac{\partial \rho}{\partial t}+\nabla \cdot(\rho \vec{V})=0 \\
\frac{\partial(\rho \vec{V})}{\partial t}+\nabla \cdot(\rho \vec{V} \vec{V})=-\nabla P+\nabla \cdot \overline{\bar{\tau}}+\rho \vec{g}+\vec{F} \\
\frac{\partial \alpha}{\partial t}+\nabla \cdot(\alpha \vec{V})=0
\end{gathered}
$$

where, $\rho$ is density $\left(\mathrm{kg} / \mathrm{m}^{3}\right) ; \vec{v}$ is velocity $(\mathrm{m} / \mathrm{s}) ; p$ is pressure $\left(\mathrm{N} / \mathrm{m}^{2}\right) ; \vec{F}$ are external body forces $\left(\mathrm{N} / \mathrm{m}^{3}\right) ; \overline{\bar{\tau}}$ the rate of deformation tensor $\left(\mathrm{N} / \mathrm{m}^{2}\right)$; and $\vec{g}$ is gravity.

Fluids properties have to be balanced inside each finite volume of the domain as following equations [38]:

$$
\begin{gathered}
\rho=\alpha \rho_{\text {water }}+(1-\alpha) \rho_{\text {air }} \\
\mu=\alpha \mu_{\text {water }}+(1-\alpha) \mu_{\text {air }}
\end{gathered}
$$

where, $\mu$ is viscosity $(\mathrm{kg} / \mathrm{m} \cdot \mathrm{s})$.

\subsection{Wave theory used for wave generation}

The mathematical model that describes linear waves yields in the following equations for the velocity field and free surface displacement of the waves [40]:

$$
\begin{gathered}
u=\frac{\pi H}{T} \frac{\cosh (h+z)}{\sinh (k h)} \cos (k x-\sigma t) \\
w=\frac{\pi H}{T} \frac{\cosh k(h+z)}{\sinh (k h)} \cos (k x-\sigma t) \\
\eta=\frac{H}{2} \cos (k x-\sigma t)
\end{gathered}
$$

where, $H$ is the wave height $(\mathrm{m}) ; \eta$ is wave free-surface elevation $(\mathrm{m})$ that is function of $x$ position (wave propagation direction, in $\mathrm{m}$ ) and time $t(\mathrm{~s}) ; \sigma=2 \pi / T$ is the wave frequency $(1 / \mathrm{s}) ; k=2 \pi / \lambda$ is the wavenumber $(1 / \mathrm{m}) ; T$ is the wave period (s); $\lambda$ is the wavelength (m), $u$ is the component velocity in $x$ direction $(\mathrm{m} / \mathrm{s})$, and $w$ is the component velocity in $z$-direction $(\mathrm{m} / \mathrm{s})$, and $h$ is the water depth $(\mathrm{m})$.

\subsection{Constructal Design}

Constructal Design is a method based on a physical principle and used to improve any flow system with finite dimensions. This physical principle is the Constructal Law, responsible for the design generation of inanimate and animate flow systems. The Constructal Law states that for a flow system to persist in time, i.e., to survive, it must evolve in such a way to provide easier access to internal currents flowing through it. For this reason, this is considered a law for the generation and evolution of design over time [31-33].

Basically, for the Constructal Design application in engineering problems, it is necessary to define constraints, a variation of degrees of freedom, and improvement of a performance indicator. A detailed procedure explaining how to apply the Constructal Design method can be found in Dos Santos et al. [34].

Therefore, in the present study, considering a generic domain depicted in Figure 1, the Constructal Design method was employed. The flow system is a $327 \mathrm{~m}$ wave channel with an OWC at the end. Besides, a ramp (representing an inclined seabed) is considered under the OWC.

From Figure 1, the present study aims to determine the optimized geometry dimensions of the hydro-pneumatic chamber $\left(H_{1}\right.$ and $\left.L_{1}\right)$ and for the seabed ramp $\left(L_{2}\right.$ and $\left.H_{2}\right)$ in terms of maximizing available power inside the turbine-duct connected to the OWC chamber. Two values for $\mathrm{H}_{3}$ (front face submergence) were tested. Therefore, for the application of the Constructal Design method, the degrees of freedom $H_{1} / L_{1}$ and $H_{2} / L_{2}$ were investigated for ten-meter-depth flume $(h=10 \mathrm{~m})$ subjected to regular incident waves series (wave height $H=1$ $\mathrm{m}$, wave period $T=7.5 \mathrm{~s}$, and wavelength $\lambda=65.4 \mathrm{~m}$ ), considering two $\mathrm{H}_{3}$ values. Three simultaneous constraints were respected: $A_{1}=80 \mathrm{~m}^{2}$ (area of the chamber), $A_{2}=40 \mathrm{~m}^{2}$ (area of the ramp beneath the chamber), and $H_{4}<\left(h-H_{3}\right)$ (prevents that frontal chamber plate of the OWC from intercepting lower ramp). 


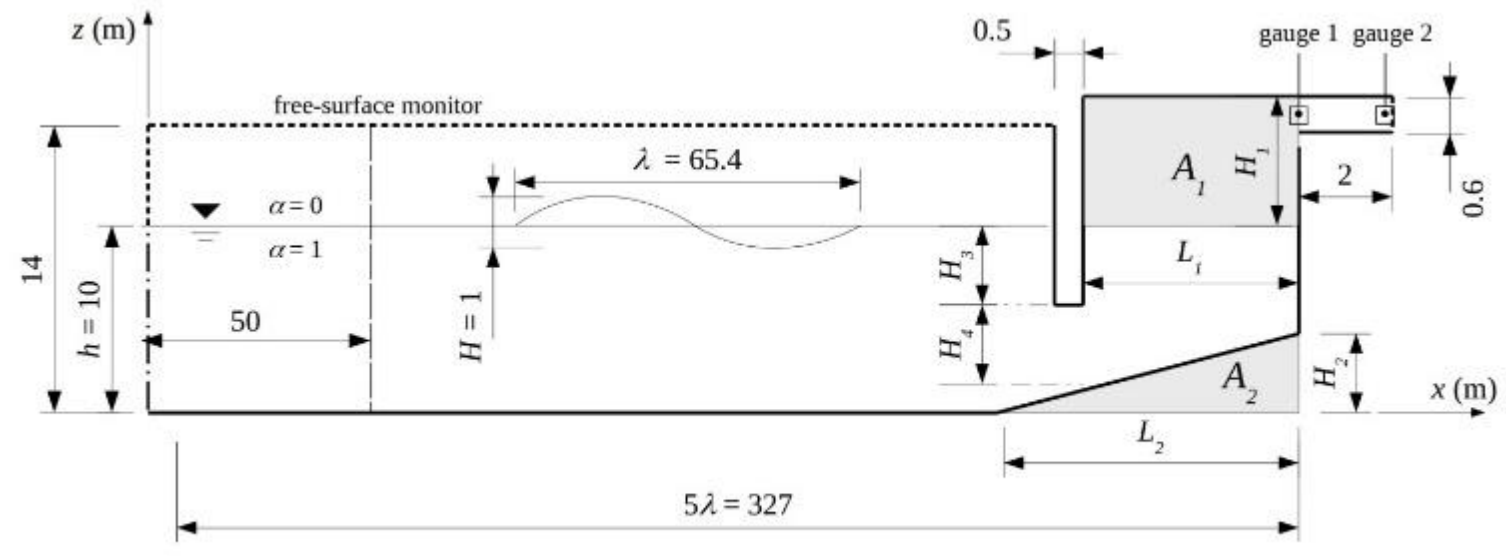

-. W. Wave-Maker BC; $\alpha=1 ; . . . . .$. Atmospheric pressure; $d \alpha / d n=0 ;-$ Null velocity; $d \alpha / d n=0 ; \quad-\quad$ Water level.

Figure 1. Computational domain of the analyzed OWC with current constrains $\left(A_{1}, A_{2}, H_{4}\right)$ and degrees of freedom $\left(H_{1} / L_{1}, H_{2} / L_{2}\right.$, $\left.\mathrm{H}_{3}\right)$

The geometric evaluation process illustrated in Figure 2, combines each chamber configuration $\left(H_{1} / L_{1}=0.2 ; 0.4 ; 0.8\right.$; $1.0 ; 2.0 ; 3.0$; and 5.0) with ramp configurations $\left(H_{2} / L_{2}=0.05\right.$; $0.1 ; 0.2 ; 0.4 ; 0.8 ;$ and 1.0$)$ for the two different values of front face submergence $\left(H_{3}=2.5 \mathrm{~m}\right.$ and $\left.5.0 \mathrm{~m}\right)$. This combination led to 112 cases that are numerically simulated and compared to each other characterizing an optimization using an exhaustive search technique. More precisely, the optimization process performed here is shared in two steps for two different magnitudes of submergence height of the frontal wall $\left(\mathrm{H}_{3}=\right.$ $2.5 \mathrm{~m}$ and $5.0 \mathrm{~m})$. In the first optimization step, the ratio $H_{1} / L_{1}$ is varied for a fixed magnitude of $H_{2} / L_{2}$. The highest OWC available power $(P)$ is the once maximized available power $\left(P_{\mathrm{m}}\right)$, and the corresponding optimal geometry is the once optimized ratio of $H_{1} / L_{1},\left(H_{1} / L_{1}\right)_{\mathrm{o}}$. In the second optimization level, the ratio $H_{1} / L_{1}$ is varied again; however, for another ratio, $\mathrm{H}_{2} / L_{2}$, keeping the submergence height $H_{3}$ constant. This process is repeated for several ratios of $H_{2} / L_{2}$. The highest magnitude of OWC available power among all cases varying $H_{1} / L_{1}$ and $H_{2} / L_{2}$ is the twice-maximized available power $\left(P_{\mathrm{mm}}\right)$, and the corresponding shapes are the twice optimized ratio of $H_{1} / L_{1}, \quad\left(H_{1} / L_{1}\right)_{\text {oo }}$, and the once optimized ratio of $H_{2} / L_{2}$, $\left(H_{2} / L_{2}\right)_{\mathrm{o}}$. The same optimization process is repeated two times for the two different submergence heights of the frontal wall $\left(\mathrm{H}_{3}\right)$.

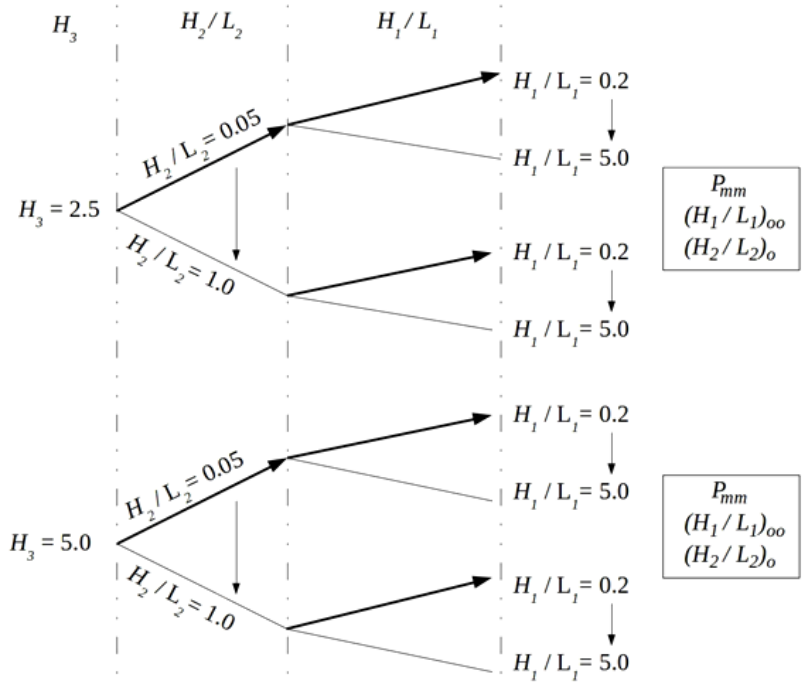

Figure 2. Flowchart of performed simulations among which OWC optimal design is determined
As mentioned above, the performance indicator adopted was the OWC available power $(P)$, which must be maximized. From the numerical results obtained for each case, $P$ is given by [18]:

$$
P=\left(\Delta p+\frac{\rho v^{2}}{2}\right) \frac{\dot{m}}{\rho}
$$

being $\Delta p$ the air pressure variation at the OWC turbine-duct $\left(\mathrm{kg} / \mathrm{m}^{3}\right)$, between gauge 1 and gauge 2 (see Figure 1 ); $\rho$ the air density $\left(\mathrm{kg} / \mathrm{m}^{3}\right) ; v$ the air velocity at the OWC turbine-duct (m\s); and $\dot{m}$ the air mass flow rate at the OWC turbine-duct. It is essential to highlight that no flow restriction representing the turbine pressure drop was considered.

\section{COMPUTATIONAL MODELING}

To solve the different cases proposed by Constructal Design, the Finite Volume Method (FVM) was used for the numerical treatment of governing equations (continuity, momentum, and volume fraction) utilizing Fluent commercial code [41], employing VOF model to treat two-phase water-air flow. Moreover, the pressure-based solver has been utilized for the simulations, the First Order Upwind scheme has been used for advective terms, and PRESTO (Pressure Staggering Option) has been adopted for spatial discretization of pressure in the momentum equation. Pressure-velocity coupling adopts PISO (Pressure Implicit Split Operator) algorithm, and the water-air interface is treated with the Geo-reconstruction method. Additionally, sub-relaxation factors of 0.3 and 0.7 were applied for conservations equations of mass and momentum, and convergence occurs for mass and momentum equations residues lower than $10^{-6}$.

The generation of regular waves in the wave channel is possible due to the left border wave-maker (dash-and-dot black line in Figure 1) that imposes the transient velocity profile corresponding to the analytical Airy wave theory, i.e., a prescribed velocity boundary condition defined by Eqns. (6) and (7). Continuous black lines are no-slip boundary conditions, and dashed black lines are boundary conditions of atmospheric pressure. These last two boundary conditions apply a normal derivative of $\alpha$ equal to zero for the VOF equation. The initial condition $(t=0 \mathrm{~s})$ takes fluids at rest, 
being the water depth of $h=10 \mathrm{~m}$.

Results were obtained by taking into account mass flow rate $(\dot{m})$ through the duct of a turbine with a length of $2.0 \mathrm{~m}$ next to the OWC chamber, which hydraulic diameter is $0.6 \mathrm{~m}$, and the pressure variation $(\Delta p)$ between gauge 1 and gauge 2 . Water free-surface displacement is monitored at $x=50 \mathrm{~m}$ from the wave-maker (see Figure 1).

About the discretization of the computational domains, this study adopts finite rectangular volumes. Figure 3 shows the entire computational domain and also a detailed section around the OWC chamber. It is noticed that refinements are applied near the walls (surfaces with no-slip and impermeability boundary conditions), at the water-air interface, and at the outward of the turbine duct (where air mass flow rate is monitored). This study follows the bibliography recommendation concerning finite volume sizes for the current simulation type [8].

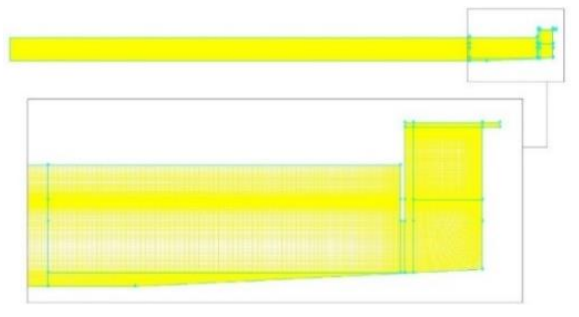

Figure 3. Spatial discretization applied to the computational domain

\subsection{Time-step convergence test and computational model verification}

Due to the unsteady behavior of the problem in the study, a time-step convergence test was performed. More precisely, the water level $(\eta)$ along the time was monitored for different time-steps. Four time-step values were tested, as indicated in Table 1. Found results are also presented in Table 1, which points out that $\Delta t=2.0 \times 10^{-2} \mathrm{~s}$ is an appropriate time-step that manages result accuracy and computational effort control. The instantaneous relative difference between two consecutive simulations $\left(\Delta t=1.0 \times 10^{-2} \mathrm{~s}\right.$ and $\left.\Delta t=2.0 \times 10^{-2} \mathrm{~s}\right)$ in timestep convergence test achieves $1 \%$ for the instant of time $t=$ $15 \mathrm{~s}$.

Table 1. Free-surface elevation $(\eta)$ at time $t=15.0 \mathrm{~s}$ for the considered time-steps.

\begin{tabular}{ccc}
\hline$\Delta \mathbf{t}(\mathbf{s})$ & $\boldsymbol{\eta}(\mathbf{m})$ & Relative difference $(\boldsymbol{\%})$ \\
\hline $5.0 \times 10^{-3}$ & 10.50779 & - \\
$1.0 \times 10^{-2}$ & 10.50777 & $1.9 \times 10^{-4}$ \\
$2.0 \times 10^{-2}$ & 10.50770 & $6.6 \times 10^{-4}$ \\
$4.0 \times 10^{-2}$ & 10.49640 & $1.1 \times 10^{-1}$ \\
\hline
\end{tabular}

Figure 4a plots free-surface displacement of the analyzed cases with different time-step sizes, being possible to observe the good agreement among solutions except for the one that applies $\Delta t=4.0 \times 10^{-2} \mathrm{~s}$. In sequence, employing $\Delta t=2.0$ $\times 10^{-2} \mathrm{~s}$, the computational model verification was performed comparing in Figure $4 \mathrm{~b}$ the free surface elevation of the water obtained with the present numerical code and the one reached with the analytical solution given by Eq. (8). One can note a good agreement between numerical and analytical results, with a minor relative difference of $5 \%$ after the numerical wave stabilization at $t=15 \mathrm{~s}$.

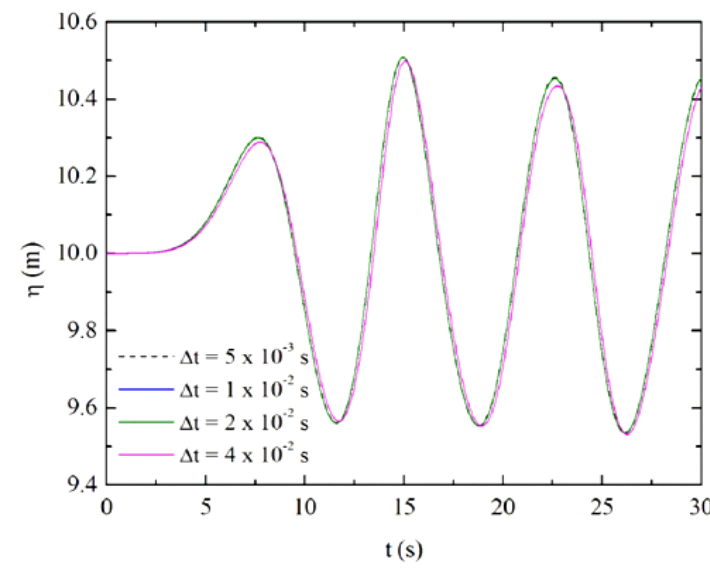

(a) Time-step convergence test

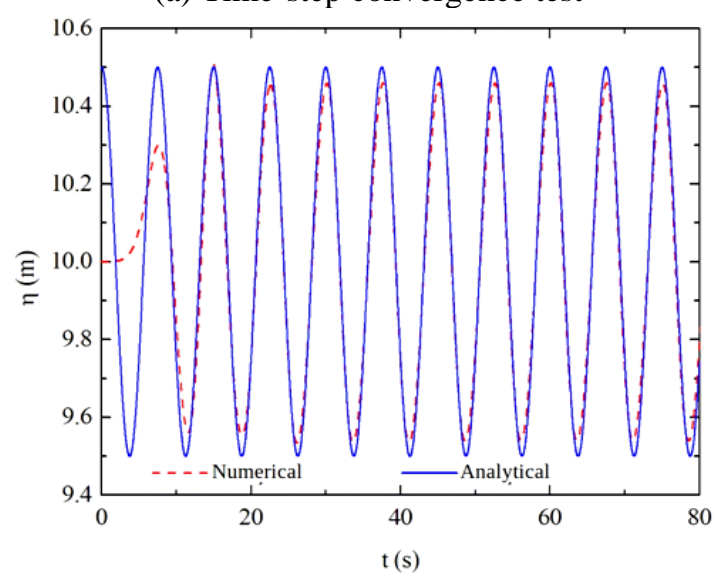

(b) Computational model verification

Figure 4. Results for wave flow in a channel

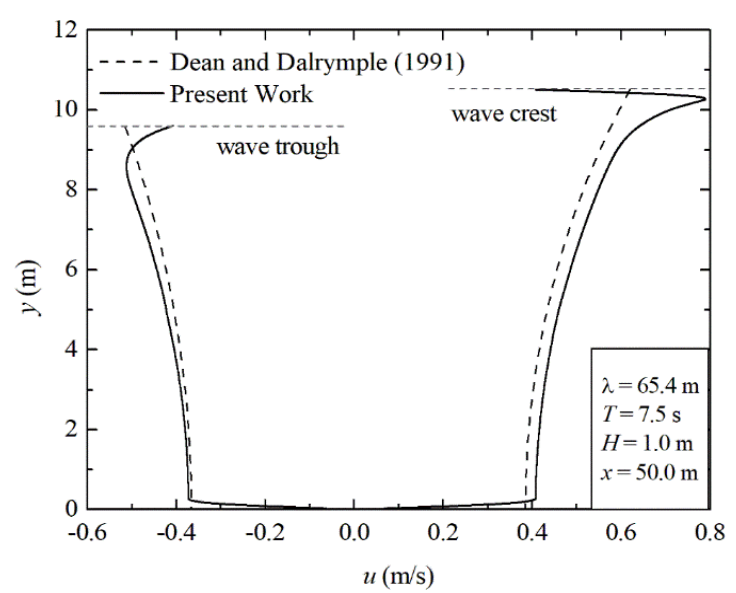

Figure 5. Comparison of velocity profile in $x$-direction below the wave crest and trough obtained with the present numerical method and analytical solution [40]

In addition to comparing instantaneous behavior of free surface elevation, Figure 5 shows two velocity profiles in $x$ direction monitored below the wave crest and trough. The monitoring line is placed at $x=50 \mathrm{~m}$ from the wave-maker of the channel. The results obtained with the present code are compared with the analytical solution of Dean and Dalrymple [40] for a potential flow. In general, the numerical results are in close agreement with the analytical ones, with a difference lower than $5.0 \%$, regardless of the profile below the crest or trough. In the lower region of the channel $(z \leq 0.5 \mathrm{~m})$, the differences found are concerned with the imposition of no-slip 
and impermeability boundary conditions in the numerical solution, which is not considered for the analytical solution since it considers a potential flow. In the region of the waterair interface $(8.5 \mathrm{~m} \leq z \leq 9.5 \mathrm{~m}$ for the trough and $9.5 \mathrm{~m} \leq z \leq$ $10.5 \mathrm{~m}$ for the crest), the differences found can be related to the density gradient which varies in the present numerical solution from water (where $\alpha=1.0$ ) to air (where $\alpha=0$ ). To comply with the mass conservation, the velocity in the interface must vary to avoid discontinuity between the air and water phases. Therefore, the differences found are related to the simplifications employed for the near-wall and water-air interface regions' potential flow. These simplifications are relaxed in the numerical solution. In the other regions, the velocity profiles are in close agreement showing that the present computational method can be adopted to represent the wave flow simulated in this work.

To validate the present numerical method for predicting of velocity and pressure fields into the OWC chamber, it was reproduced a case study investigated numerically and experimentally by Liu et al. [42]. It is worth mentioning that this comparison was previously performed in the work of Gomes et al. [35] with the same numerical code. Consequently, the same results obtained by Gomes et al. [35] are achieved here.

More precisely, it is simulated the wave flow in a channel with length and height of $700.0 \mathrm{~m}$ and $30.0 \mathrm{~m}$, respectively. The water column's depth is $16.0 \mathrm{~m}$, and the generated wave has a height of $2.0 \mathrm{~m}$ and nine different periods (in the range $3.5 \mathrm{~s} \leq T \leq 8.0 \mathrm{~s}$ ). At the end of the channel, it is placed an OWC device with a length of $6.0 \mathrm{~m}$, frontal plate length of 1.0 $\mathrm{m}$, and a height of $5.6 \mathrm{~m}$. In the chamber's upper surface, a chimney is placed with a diameter of $2.5 \mathrm{~m}$ and a length of 6.5 $\mathrm{m}$. It is not used for any obstacle or turbine in the chimney region. The averaged magnitudes of positive and negative amplitudes of the air pressure and velocity variations in the chamber were monitored for different wave periods. The results were compared with those obtained numerically and experimentally by Liu et al. [42]. The numerical results of Liu et al. [42] were simulated using the Reynolds-Averaged Navier Stokes (RANS) approach with the $k-\varepsilon$ model for the closure of time-averaged equations. In the present approach, the fluid flow is considered laminar and incompressible.

The comparison between the velocity and pressure fields obtained with the present code and those predicted by Liu et al. [42] are presented in Figures 6(a) and 6(b), respectively. For the velocity field, Figure 6(a), results indicated that the two-dimensional cases slightly overestimate the magnitudes of velocities in the chamber in the range $5.5 \mathrm{~s} \leq T \leq 7.0 \mathrm{~s}$. Moreover, the velocities predicted here have intermediate magnitudes between the 2D and 3D results of Liu et al. [42]. For pressure fields, Figure 6(b), results obtained here are in good agreement with experimental and 3D numerical results of Liu et al. [33]. The 2D results of Liu et al. [42] led to an overestimation of pressure fields, similar to that of velocity fields. Despite some differences reached between the results of the present method and those predicted by Liu et al. [42], in general, the results are in close agreement, indicating the validity of the present method for the flow conditions studied in the present work. This is an important observation since considering the three-dimensional domain, turbulent and incompressible flows would significantly enlarge the computational effort, making the geometrical evaluation performed in the present study unfeasible.

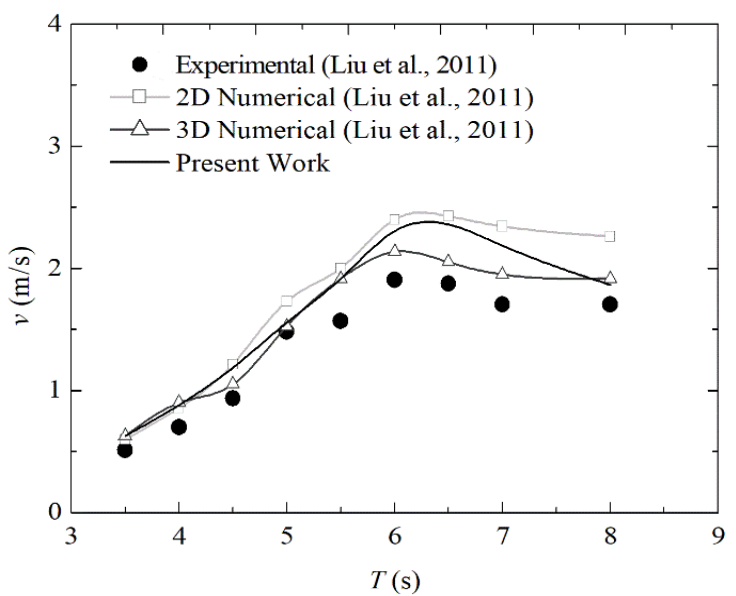

(a) Velocity magnitudes

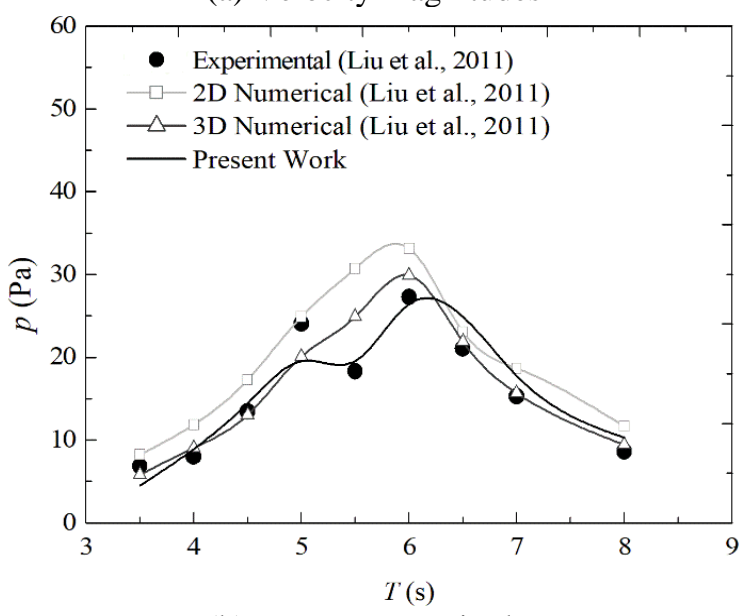

(b) Pressure magnitudes

Figure 6. Comparison between the present and Liu et al. [42] results in an OWC for various wave periods

\section{RESULTS AND DISCUSSION}

Initially, it was numerically analyzed the performance of the reference case in which there is no ramp below the OWC chamber, being $A_{2}=H_{2} / L_{2}=0$ (see Figure 1). It was evaluated the $H_{1} / L_{1}$ effect over the available power of the device with $H_{3}$ $=2.5 \mathrm{~m}$. Results are shown for the mass flow rate (Figure 7a) and pressure variation (Figure $7 \mathrm{~b}$ ) of air along time. Figure 7 presents three values of the $H_{1} / L_{1}$ ratio, representing the geometric extremes $\left(H_{1} / L_{1}=0.2\right.$ and 5.0) and the geometric configuration that achieved the maximum available power $\left(\left(H_{1} / L_{1}\right)_{o}=0.4\right)$.

From Figure 7a, a general symmetric oscillating behavior can be identified in mass flow rate for three $H_{l} / L_{1}$ presented conditions with straight convergence in time, i.e., the results are in phase. It is also observed that the $H_{1} / L_{l}=5.0$ case achieved the worse results once the mass flow rate is integrally inferior to two other cases, for example, almost two times less than the best case at instant $t=57.5 \mathrm{~s}$. In this way, it is noticed that $H_{l} / L_{1}=0.2$ and 0.4 presented similar comportment. However, $H_{l} / L_{1}=0.4$ has a specific performance superiority. Therefore, results indicate that higher chambers hinder that the airflow achieves the turbine-duct coupled to the hydropneumatic chamber. 


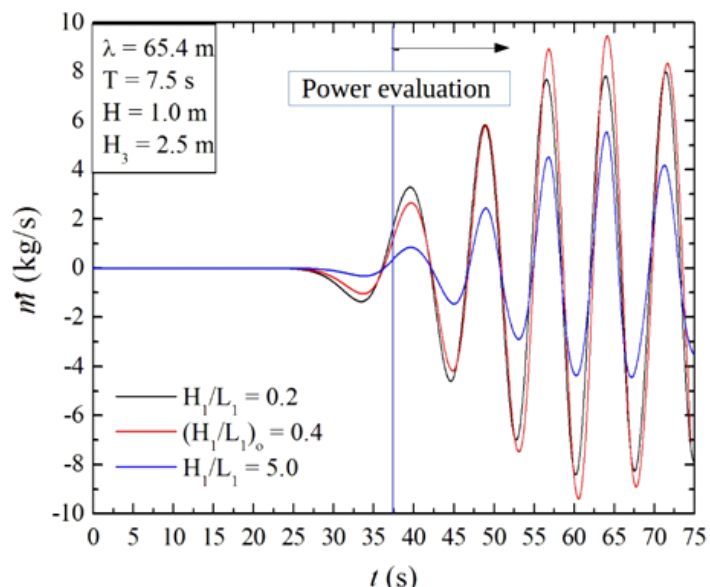

(a) Mass flow rate

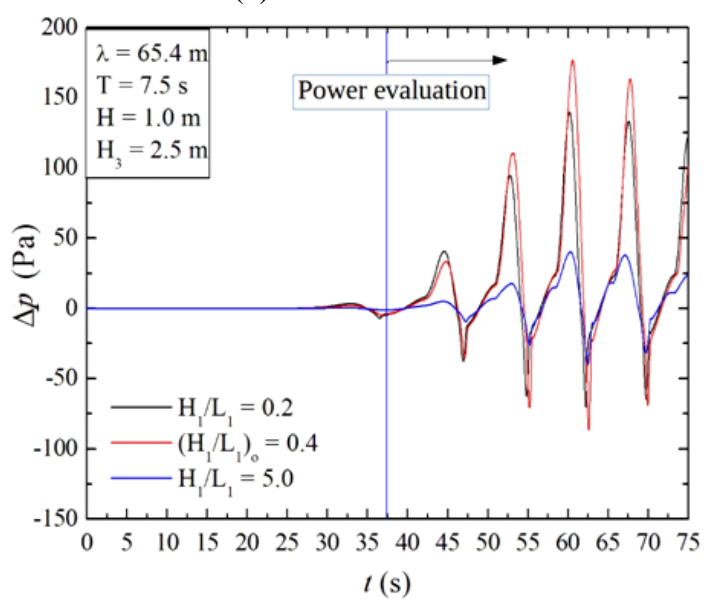

(b) Pressure variation

Figure 7. Transient results of the reference case $\left(H_{2} / L_{2}=0\right)$ with $H_{1} / L_{1}=0.2,0.4$, and 5.0 for $H_{3}=2.5 \mathrm{~m}$

Regarding the pressure variation analysis, Figure $7 \mathrm{~b}$ shows an asymmetric oscillating behavior with more significant magnitudes when the mass flow rate is positive (flowing in the positive $x$-direction, outward the chamber). That probably occurs because the airflow meets atmospheric pressure when flowing in the positive $x$-direction (outward), which offers less resistance; since the airflow in the negative $x$-direction (flow back) is submitted to the more elevated internal chamber pressure. Besides, Figure 7 indicates that the mass flow rate and pressure variation seem to present a similar response to geometry changes. It is observed that geometric configuration with $\left(H_{1} / L_{1}\right)_{o}=0.4$ also offers more considerable pressure variation inside the duct after the first incident wave (after $t=$ $47 \mathrm{~s})$.

Figure 8 a presents RMS available power $\left(P_{\mathrm{RMS}}\right)$ concerning time for the same cases of Figure 7, still considering the no ramp reference case. Hence, the behavior follows the pressure variation aspect above mentioned (see Figure 7b), with higher peaks according to outward mass flow rate, as well as geometry $\left(H_{1} / L_{1}\right)_{o}=0.4$ achieving the best performance while $H_{1} / L_{1}=0.5$ worsened the performance of the OWC converter.

In its turn, Figure $8 \mathrm{~b}$ plots average available power of all studied $H_{1} / L_{1}$ ratios $(0.2 ; 0.4 ; 0.8 ; 1.0 ; 1.5 ; 2.0 ; 3.0$; and 5.0$)$. One can note that $\left(H_{1} / L_{1}\right)_{o}=0.4$ achieved the best performance, generating a maximized available power of $P_{m}=240.88 \mathrm{~W}$; while geometry $H_{1} / L_{1}=0.2$ achieved $P=206.13 \mathrm{~W}(17 \%$ difference) and geometry $H_{1} / L_{1}=5.0$ got $P=31.34 \mathrm{~W}$ being the worst performance.

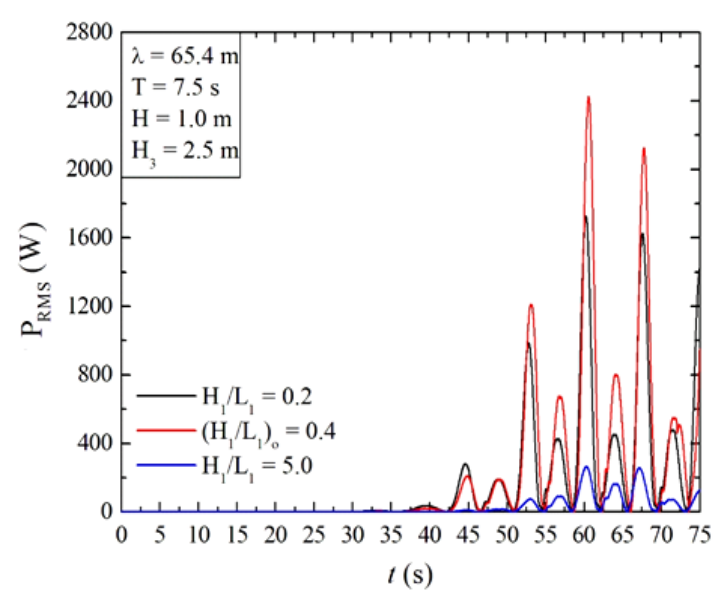

(a) Transient RMS available power

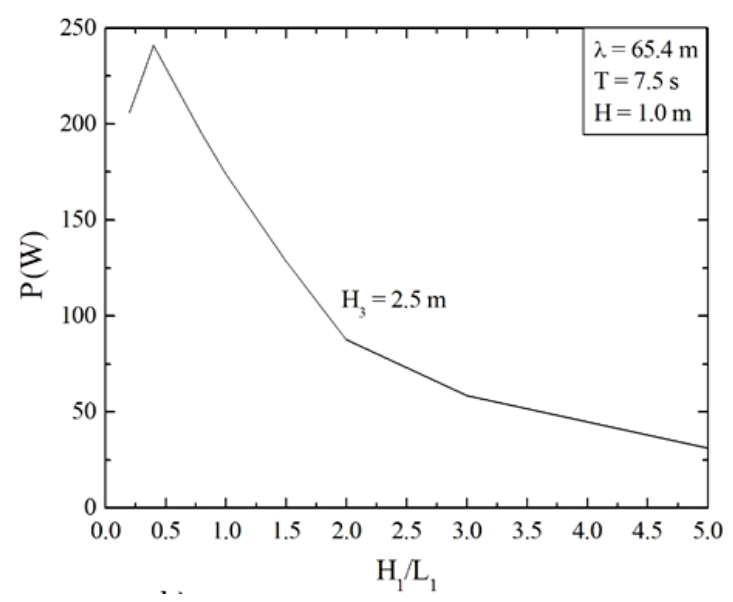

(b) Time-averaged RMS available power

Figure 8. Results of the reference case $\left(H_{2} / L_{2}=0\right)$ for different ratios of $H_{1} / L_{1}$ and $H_{3}=2.5 \mathrm{~m}$

To evaluate the effect of setting a ramp below the OWC chamber, Figures $9 \mathrm{a}$ and $9 \mathrm{~b}$ compare mass flow rate and pressure variation between reference case (without ramp, $A_{2}=$ $H_{2} / L_{2}=0$ ) and Figure 1 described case (with $A_{2}=40 \mathrm{~m}^{2}$ and $H_{2} / L_{2}=0.8$ ). The other degrees of freedom adopted for this comparison are $H_{1} / L_{1}=0.2$ and $H_{3}=2.5 \mathrm{~m}$.

From Figure 9, it is possible to observe that ramp usage promotes a magnitude increase in both operational parameters $\left(\mathrm{m}^{\circ}\right.$ and $\left.\Delta \mathrm{p}\right)$. Besides, general graphs aspects are very similar to those presented in Figure 7, where higher magnitudes were found at outward airflow instants. After that, the ramp's effect over the converter RMS available power along time can be viewed in Figure 10. Figure 10 indicates an improvement of the RMS available power due to ramp usage. Moreover, more significant peaks are identified at outward airflow instants as well.

Based on these preliminary results, it is relevant to investigate the influence of OWC chamber geometry $\left(H_{1} / L_{1}\right)$ over its average available power when associated with different seabed ramp configurations $\left(\mathrm{H}_{2} / \mathrm{L}_{2}\right)$. These results are plotted in Figure 11, considering $H_{3}=2.5 \mathrm{~m}$. The reference case results, earlier presented in Figure $8 \mathrm{~b}$, are also plotted in Figure 11, aiming to help the discussion.

One can infer in Figure 11 that the maximum values for the OWC available power were always reached for a specific value of $H_{1} / L_{1}$ ratio, independently of $H_{2} / L_{2}$. Hence, its once optimized value is $\left(H_{1} / L_{1}\right)_{o}=0.4$, being the same configuration that optimizes the reference case. The $H_{2} / L_{2}$ effect analysis of 
Figure 11 shows that ramp insertion benefits the device with more meaningful average power for all $H_{1} / L_{1}$ cases compared with the reference case. Additionally, power increment for $H_{2} / L_{2}>0.2$ occurs significantly around optimal geometry, i.e., $\left(H_{1} / L_{1}\right)_{\mathrm{o}} \approx 0.4$. It is also noticed that higher $H_{1} / L_{1}$ values $\left(H_{1} / L_{1}>\right.$ 1.5) present very close performances regardless of the $H_{2} / L_{2}$ ratio. Therefore, for $H_{3}=2.5 \mathrm{~m}$, the ramp showed more effectiveness in the optimal region of the ratio $H_{l} / L_{l}$.

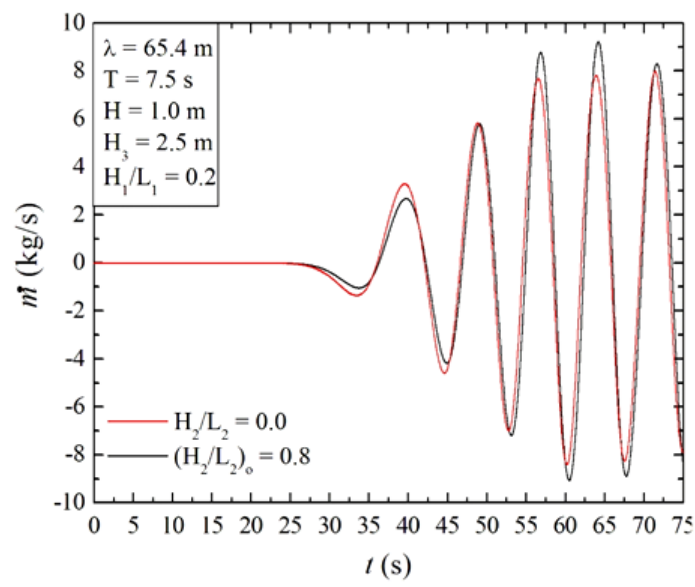

(a) Mass flow rate

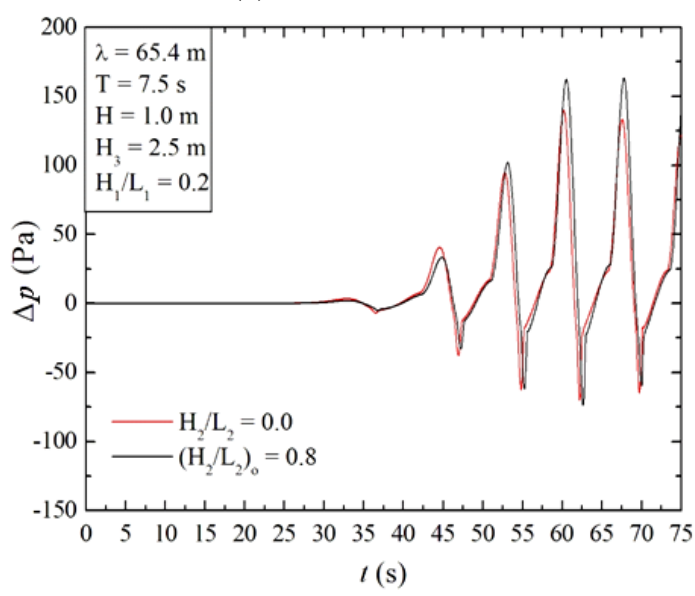

(b) Pressure variation

Figure 9. Comparison between transient results of reference case and the case with $H_{2} / L_{2}=0.8$, considering $H_{1} / L_{1}=0.2$ and $H_{3}=2.5 \mathrm{~m}$

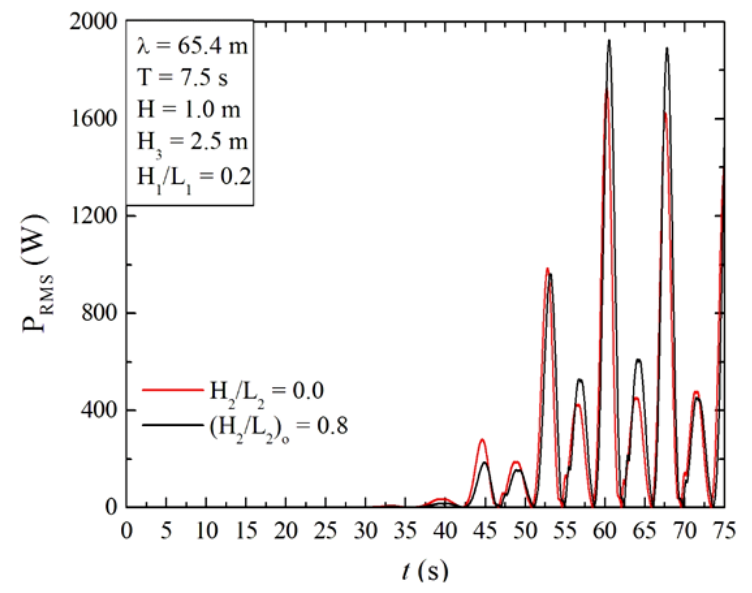

Figure 10. Comparison between transient results of the reference case and the case with $H_{2} / L_{2}=0.8$, considering $H_{1} / L_{1}=0.2$ and $H_{3}=2.5 \mathrm{~m}$ for RMS available power

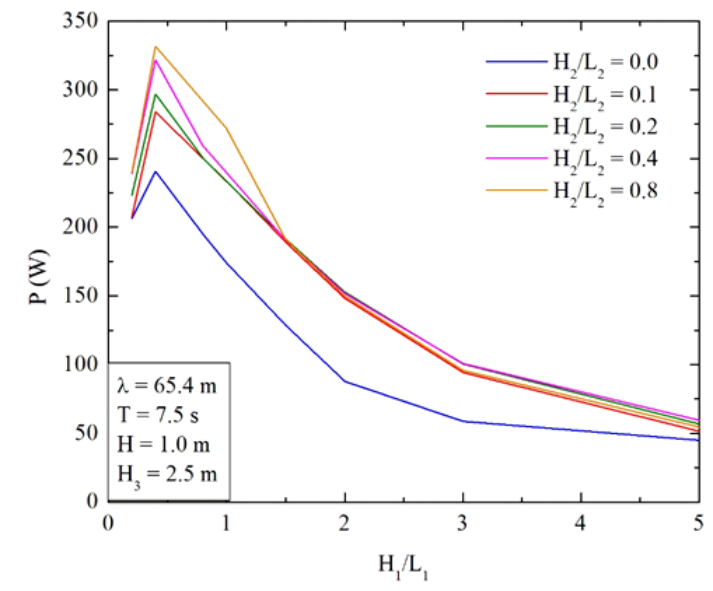

Figure 11. Effect of $H_{1} / L_{1}$ over available power for different $H_{2} / L_{2}$ ratios and $H_{3}=2.5 \mathrm{~m}$

Still looking at Figure 11, in a general way, the increase of the $H_{2} / L_{2}$ ratio promotes an augmentation in OWC available power. Therefore, it is possible to define the twice optimized chamber geometry and the once optimized ramp geometry given, respectively, by $\left(H_{1} / L_{1}\right)_{o o}=0.4$ and $\left(H_{2} / L_{2}\right)_{o}=0.8$; reaching a twice maximized average power of $P_{m m}=331.57$ $\mathrm{W}$. If this value is compared with the maximum average power for the reference case $\left(P_{m}=240.88 \mathrm{~W}\right)$, an improvement of $37.7 \%$ was achieved.

Beyond evaluated operational work parameters, it was also presented phase fraction and velocity fields. It was adopted the time instant of $68 \mathrm{~s}$, the optimized OWC chamber geometry of $\left(H_{1} / L_{1}\right)_{o}=0.4$, and the submergence of frontal plate chamber of $H_{3}=2.5 \mathrm{~m}$. In addition, three values for the seabed ramp geometry were considered: $H_{2} / L_{2}=0.05$ (Figure 12), $H_{2} / L_{2}=$ 0.2 (Figure 13), and $\left(H_{2} / L_{2}\right)_{o o}=0.8$ (Figure 14).

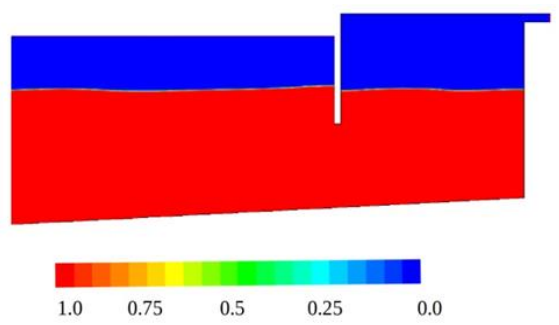

(a) Phase fraction field

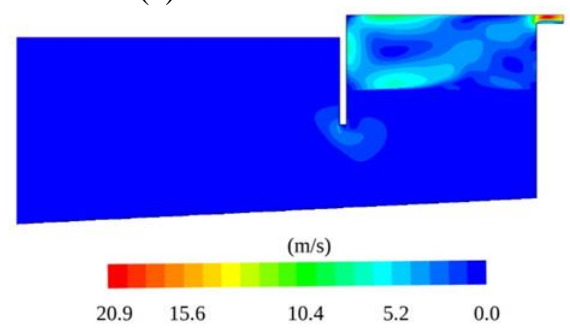

(b) Velocity field

Figure 12. Geometric configuration with $\left(H_{1} / L_{1}\right)_{o}=0.4$, $H_{2} / L_{2}=0.05$, and $H_{3}=2.5 \mathrm{~m}$ for $t=68.0 \mathrm{~s}$

Figures 12a, 13a, and 14a (where red and blue colors represent, respectively, water and air phases) show a wave crest interacting with the optimized OWC configuration, causing the water level elevation inside the hydro-pneumatic chamber, which forces airflow passage outward the turbineduct. One can observe this airflow in the velocity fields of Figures 12b, 13b, and 14b, respectively. It is also possible to 
notice that the $H_{2} / L_{2}$ ratio increases promote an increase of the velocity magnitude, showing a consistent behavior with previous analyzes about power performance.

The presented results so far were obtained for $H_{3}=2.5 \mathrm{~m}$. Now, these same analyses were carried out using an OWC frontal wall with $H_{3}=5.0 \mathrm{~m}$, aiming to identify how this geometric parameter influences the fluid-dynamic behavior of the converter associated with the seabed ramp. Therefore, Figure 15 plots the $H_{1} / L_{1}$ ratio's effect over average available power for all tested $H_{2} / L_{2}$ ratios, considering $H_{3}=5.0 \mathrm{~m}$.

As depicted in Figure 15, for the reference case $\left(H_{2} / L_{2}=0\right)$, the $H_{1} / L_{1}$ effect over $P$ is similar to the effect over the reference case with $H_{3}=2.5 \mathrm{~m}$ (see Figure 11), but here a lower value for the maximized available power is obtained. Therefore, the optimal chamber configuration suffers the influence of the front wall magnitude, being observed that the reference case achieves a maximum power of $145.10 \mathrm{~W}$, i.e., $39.7 \%$ lower than the best case with $H_{3}=2.5 \mathrm{~m}$. Moreover, the optimized $H_{1} / L_{1}$ ratio is changed from 0.4 (for $H_{3}=2.5 \mathrm{~m}$ ) to 1.0 when $H_{3}=5.0 \mathrm{~m}$ is applied.

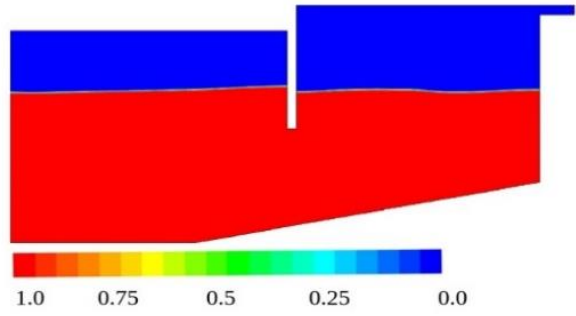

(a) Phase fraction field

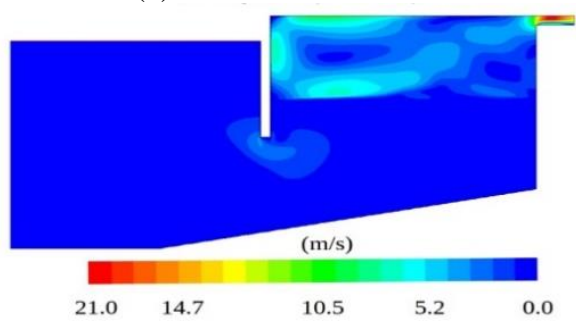

(b) Velocity field

Figure 13. Geometric configuration with $\left(H_{1} / L_{1}\right)_{o}=0.4$, $H_{2} / L_{2}=0.2$, and $H_{3}=2.5 \mathrm{~m}$ for $t=68.0 \mathrm{~s}$

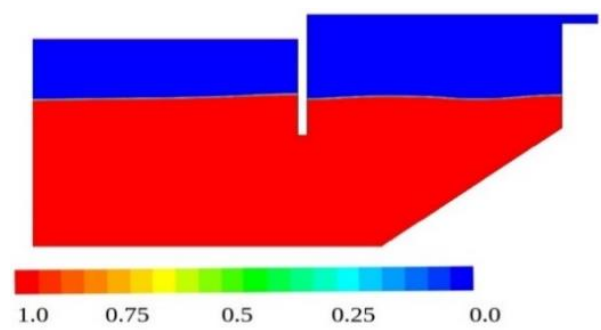

(a) Phase fraction field

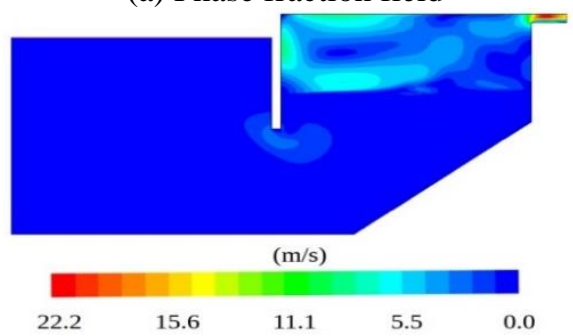

(b) Velocity field

Figure 14. Geometric configuration with $\left(H_{1} / L_{1}\right)_{o}=0.4$, $\left(H_{2} / L_{2}\right)_{o o}=0.8$, and $H_{3}=2.5 \mathrm{~m}$ for $t=68.0 \mathrm{~s}$

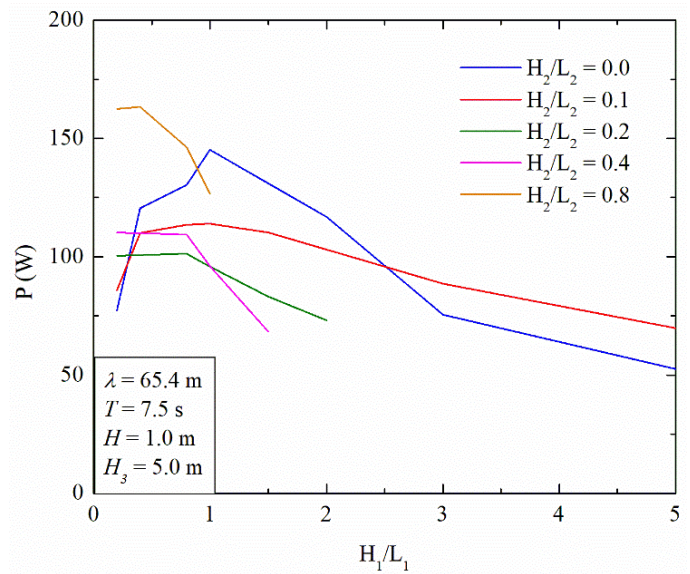

Figure 15. Effect of $H_{1} / L_{1}$ over available power for different $H_{2} / L_{2}$ ratios and $H_{3}=5.0 \mathrm{~m}$

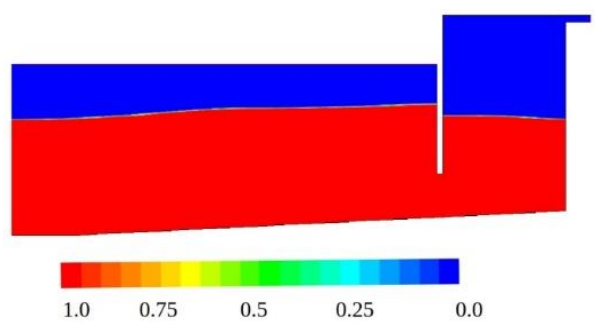

(a) Phase fraction field

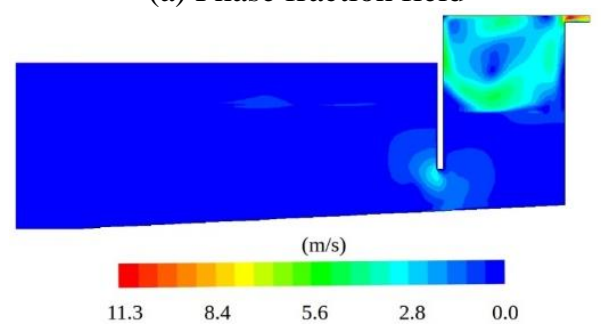

(b) Velocity field

Figure 16. Geometric configuration with $H_{1} / L_{1}=0.8, H_{2} / L_{2}$ $=0.05$, and $H_{3}=5.0 \mathrm{~m}$ for $t=68.0 \mathrm{~s}$

Figure 15 also indicates that most of the analyzed cases with a ramp obtained worse available power response than the reference case without a ramp. Considering the maximum available power of reference case, one can note that the only configurations that improve the OWC performance due to seabed ramp usage are composed of $H_{2} / L_{2}=0.8$ in the range $0.2 \leq H_{1} / L_{1} \leq 0.8$. It is important to mention that the $H_{4}<(h-$ $H_{3}$ ) constraint (as described in section 2.3) restricted interval values of $H_{1} / L_{1}$ for $H_{2} / L_{2}>0.1$. Moreover, it is observed that there is no global $H_{1} / L_{1}$ optimal ratio. However, twice maximized power $\left(P_{m m}=163.42 \mathrm{~W}\right)$ is achieved for $\left(H_{1} / L_{1}\right)_{o o}$ $=0.4$ and $\left(H_{2} / L_{2}\right)_{o}=0.8$ and, being nearly three times superior to obtained power with the worst geometry. Lastly, the twice maximized power obtained with $\mathrm{H}_{3}=5.0 \mathrm{~m}$ is $50.7 \%$ lower than the previously obtained twice maximized available power considering $H_{3}=2.5 \mathrm{~m}$ (see Figure 11), what means that increasing the vertical dimension of the OWC frontal wall conducted to poor performance for the presented conditions.

To understand the fluid-dynamic behavior of the OWC converter having a frontal plate with $H_{3}=5.0 \mathrm{~m}$, the phase fraction and velocity fields were illustrated. Again, the time instant of $68.0 \mathrm{~s}$ was adopted. Figure 16 presents the geometric configuration with $H_{1} / L_{1}=0.8$ and $H_{2} / L_{2}=0.05$; while Figure 17 shows the optimized geometry with $\left(H_{1} / L_{1}\right)_{o}=0.4$ and $\left(H_{2} / L_{2}\right)_{o o}=0.8$. 


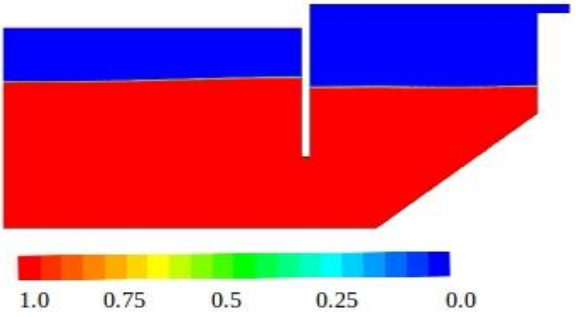

(a) Phase fraction field

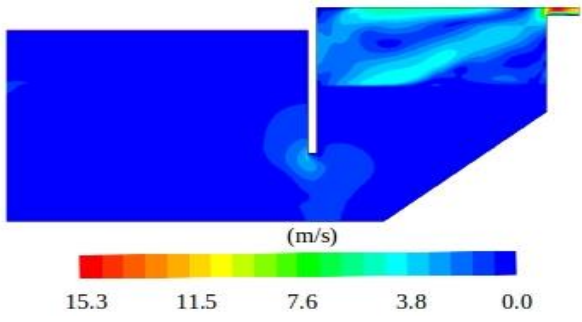

(b) Velocity field

Figure 17. Geometric configuration with $\left(H_{1} / L_{1}\right)_{o}=0.4$, $\left(H_{2} / L_{2}\right)_{\mathrm{oo}}=0.8$, and $H_{3}=5.0 \mathrm{~m}$ for $t=68.0 \mathrm{~s}$

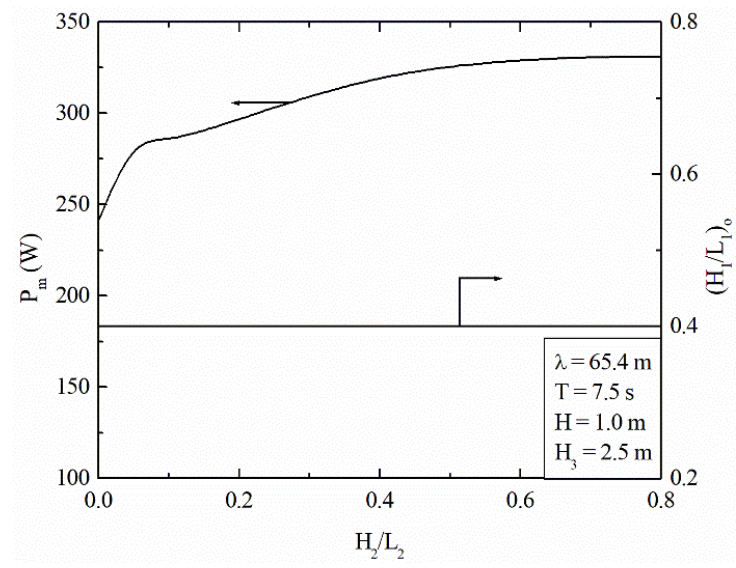

(a) $H_{3}=2.5 \mathrm{~m}$

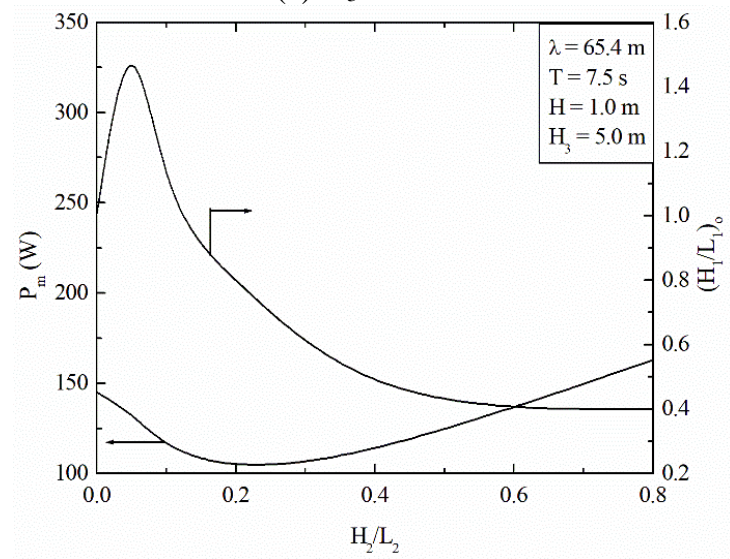

(b) $H_{3}=5.0 \mathrm{~m}$

Figure 18. Effect of $H_{2} / L_{2}$ ratio over once maximized available power $\left(P_{m}\right)$ and once optimized height/length chamber ratio $\left(H_{1} / L_{1}\right)_{o}$

The same trend is perceived in Figures 12, 13, and 14, and it can also be observed in Figures 16 and 17. Therefore, in a general way, the results show that longer ramps do not benefit the OWC purpose, causing hydro-pneumatic effect loss (see Figure 16). On the other hand, when the seabed ramp is smaller than the device chamber, the water level elevations are intensified, and airflow velocity magnitude increases inside the turbine-duct (see Figure 17).
Optimal results plotted in Figures 11 and 15 for both front wall submersions $(\mathrm{H} 3=2.5 \mathrm{~m}$ and $\mathrm{H} 3=5.0 \mathrm{~m})$ are summarized in Figures $18 \mathrm{a}$ and $18 \mathrm{~b}$, respectively. More precisely, Figure 18a depicts the effect of H2/L2 ratio over once maximized power $(\mathrm{Pm})$ and once optimized (H1/L1)o ratio for $\mathrm{H} 3=2.5 \mathrm{~m}$, while Fig $16 \mathrm{~b}$ depicts the same effect for $\mathrm{H} 3=5.0 \mathrm{~m}$.

From Figure 18a, it is observed that optimal chamber configuration is not affected by the ramp's configuration, i.e., the optimal $H_{1} / L_{1}$ ratio is constant $\left(\left(H_{1} / L_{1}\right)_{o}=0.4\right)$ for all tested values of $H_{2} / L_{2}$. Moreover, as earlier mentioned, the twice maximized average available power of $P_{m m}=331.57 \mathrm{~W}$ can be identified with twice optimized OWC chamber geometry of $\left(H_{1} / L_{1}\right)_{o o}=0.4$ and once optimized ramp geometry of $\left(H_{2} / L_{2}\right)_{o}$ $=0.8$ for $H_{3}=2.5 \mathrm{~m}$.

Otherwise, Figure $18 \mathrm{~b}$ shows that optimal chamber geometry varies significantly due to ramp configuration, achieving maximum local performance for the reference case $\left(H_{2} / L_{2}=0.0\right)$. However, for $H_{3}=5.0 \mathrm{~m}$ the maximum global performance of $P_{m m}=163.42 \mathrm{~W}$ is also obtained when $\left(H_{1} / L_{1}\right)_{o o}=0.4$ and $\left(H_{2} / L_{2}\right)_{o}=0.8$.

As in the present study, only two values of $\mathrm{H}_{3}$ were adopted, it is not possible to indicate an optimized value for this degree of freedom. However, results obtained here indicated that the wall length has a strong influence over the device performance and the effect of other degrees of freedom $\left(H_{1} / L_{1}\right.$ and $\left.H_{2} / L_{2}\right)$ over the available power.

\section{CONCLUDING REMARKS}

Based on the Constructal Design method, the geometric configuration of an onshore OWC with large scale dimensions was evaluated using $H_{1} / L_{1}$ ratio (height/length ratio of the chamber) and $H_{3}$ (Submersion of the frontal wall of the device) associated with the variation of $H_{2} / L_{2}$ ratio (height/length ratio of the seabed ramp). Two constraints were also adopted: the chamber's internal area $\left(A_{1}\right)$ and the area of the seabed ramp $\left(A_{2}\right)$. As a reference, a case with no seabed ramp $\left(H_{2} / L_{2}=0\right)$ below the OWC was adopted for each $\mathrm{H}_{3}$ value. A finitevolume computational model was used to solve the fluiddynamic problem concerning the regular wave incidence over the OWC converter. The results of all proposed geometries were compared, aiming to maximize the available power $(P)$ of the device, characterizing an optimization employing the Exhaustive Search technique.

Among studied geometric configurations, the global optimized geometry is defined by $\left(H_{1} / L_{1}\right)_{o o}=0.4,\left(H_{2} / L_{2}\right)_{o}=$ 0.8 , and $H_{3}=2.5 \mathrm{~m}$ which reaches $P_{m m}=331.57 \mathrm{~W}$. This bestcase improves $37.3 \%$ and $50.7 \%$ the OWC performance if compared, respectively, with its reference case (with no ramp) and with the best case for $H_{3}=5.0 \mathrm{~m}$ defined by $\left(H_{1} / L_{1}\right)_{o o}=$ 0.4 and $\left(H_{2} / L_{2}\right)_{o}=0.8$.

It is worth to highlight that $H_{1} / L_{1}=0.4$ conducts to superior performances for all values of $H_{2} / L_{2}$ ratio when $H_{3}=2.5 \mathrm{~m}$ (see Figures 11 and 18a), as well as for the best case among geometries with $\mathrm{H}_{3}=5.0 \mathrm{~m}$ (see Figures 15 and $18 \mathrm{~b}$ ).

Concerning to $H_{2} / L_{2}$ effect, in a general way, it is possible to affirm that the employment of a seabed ramp below the OWC converter can improve its performance. This trend is evident for cases having $H_{3}=2.5 \mathrm{~m}$ (see Figure 11). However, when $H_{3}=5.0 \mathrm{~m}$, only some geometries presented improvements if compared with its reference case.

Therefore, the influence of OWC geometry over its fluiddynamic behavior is a relevant research subject. Regarding the 
$H_{3}$ parameter, its variation has a significant effect over the OWC available power and the effect of ratios $H_{1} / L_{1}$ and $H_{2} / L_{2}$ over the available power, deserving further investigation in future work.

\section{ACKNOWLEDGMENT}

R. G. Hübner thanks $\mathrm{CNPq}$ for the master sciences scholarship. L. A. O. Rocha (307791/2019-0), L. A. Isoldi (306012/2017-0), and E. D. dos Santos (Process 306024/20179) thank $\mathrm{CNPq}$ for the research grants. L. A. Isoldi thanks FAPERGS for the financial support (Process 17/2551-0001111-2). E. D. dos Santos thanks CNPq for the financial support (Process: 440010/2019-5). The authors also thank CAPES for financial support. E.D. dos Santos thank CNPq for financial support.

\section{REFERENCES}

[1] Mørk, G., Barstow, S., Kabuth, A., Pontes, M.T. (2010). Assessing the global wave energy potential. Proceedings of 29th International Conference on Ocean, Offshore Mechanics and Arctic Engineering - OMAE 2010, pp. 447-454. https://doi.org/10.1115/OMAE2010-20473

[2] Barstow, S., Gunnar, M., Mollison, D., Cruz, J. (2008). The Wave Energy Resource. In: Cruz, J. (ed.), Ocean Wave Energy. Springer, Berlin.

[3] Evans, D.V., Porter, R. (1995). Hydrodynamic characteristics of an oscillating water column device. Applied Ocean Research, 17(3): 155-164. https://doi.org/10.1016/0141-1187(95)00008-9

[4] Lisboa, R.C., Teixeira, P.R.F., Fortes, C.J. (2017). Numerical evaluation of wave energy potential in the south of Brazil. Energy, 121: 176-184. https://doi.org/10.1016/j.energy.2017.01.001

[5] Gunn, K., Stock-Williams, C. (2012). Quantifying the global wave power resource. Renewable Energy, 44: 296-304. https://doi.org/10.1016/j.renene.2012.01.101

[6] Horko, M. (2007). CFD Optimization of an Oscillating Water Column Energy Converter. M.Sc. Dissertation. The University of Western, Australia.

[7] Falcão, A.F.O. (2010). Wave energy utilization: A review of the technologies. Renewable Sustainable Energy Reviews, 14(3): 899-918. https://doi.org/10.1016/j.rser.2009.11.003

[8] Teixeira, P.R.F., Davyt, D.P., Didier, E., Ramalhais, R. (2013). Numerical simulation of an oscillating water column device using a code based on Navier-Stokes equations. $\quad$ Energy, 61: 513-530. https://doi.org/10.1016/j.energy.2013.08.062

[9] Martins, J.C., Goulart, M.M., Gomes, M.N., Souza, J.A., Rocha, L.A.O., Isoldi, L.A., Dos Santos, E.D. (2018). Geometric evaluation of the main operational principle of an overtopping wave energy converter by means of constructal design. Renewable Energy, 118: 727-741. https://doi.org/10.1016/j.renene.2017.11.061

[10] Barbosa, D., Santos, A.L.G., Dos Santos, E.D., Souza, J.A. (2019). Overtopping device numerical study: Openfoam solution verification and evaluation of curved ramps performances. International Journal of Heat and Mass Transfer, 131: 441-423. https://doi.org/10.1016/j.ijheatmasstransfer.2018.11.071
[11] Windt, C., Davidson, J., Ringwood, J.V. (2018). Highfidelity numerical modelling of ocean wave energy systems: A review of computational fluid dynamicsbased numerical wave tanks. Renewable Sustainable Energy Reviews, 93: 610-630. https://doi.org/10.1016/j.rser.2018.05.020

[12] Bryden, I.G. (2009). Progress towards a viable UK marine renewable energy. Proceedings of ICE Conference Coasts, Marine Structures \& Breakwaters, Edinburg, pp. 2-13.

[13] Müller, G., Whittaker, T.J.T. (1995). Field measurements of breaking wave loads on a shoreline wave power station. Proceedings of ICE Water, Maritime and Energy, 112(3): 187-197. https://doi.org/10.1680/iwtme.1995.27881

[14] Müller, G., Whittaker, T.J.T. (1996). An evaluation of design wave impact pressures. Journal of Waterway, Port, Coastal and Ocean Engineering, 122(1): 55-58.

[15] Patterson, C., Dunsire, R., Hillier, S. (2009). Development of wave energy breakwater at Siadar, isle of Lewis. Proceedings of ICE Conference Coasts, Marine Structures \& Breakwaters, Edinburg, pp. 738-749. https://doi.org/10.1680/cmsb.41301.0065

[16] Torre-Enciso, Y., Marqués, J., López de Aguileta, L.I. (2010). Mutriku. Lessons learnt. $3^{\text {rd }}$ International Conference on Ocean Energy, Bilbao, pp. 1-6.

[17] Torre-Enciso, Y., Ortubia, I., López de Aguileta, L.I., Marqués. J. (2009). Mutriku Wave Power Plant: from the thinking out to the reality. Proceedings of $8^{\text {th }}$ European Wave and Tidal Energy Conference, Uppsala, pp. 319329.

[18] Dizadji, N., Sajadian, S.E. (2011). Modeling and optimization of the chamber of OWC system. Energy, 36(5): 2360-2366. https://doi.org/10.1016/j.energy.2011.01.010

[19] Mahnamfar, F., Altunkaynak, A. (2016). OWC-Type wave chamber optimization under series of regular waves. Arabian Journal of Science Engineering, 41: 1543-1549. https://doi.org/10.1007/s13369-015-1691-0

[20] Viviano, A., Naty, S., Foti, E., Bruce, T., Allsop, W., Vicinanza, D. (2016). Large-scale experiments on the behaviour of generalised Oscillating Water Column under random waves. Renewable Energy, 99: 875-887. https://doi.org/10.1016/j.renene.2016.07.067

[21] Mahnamfar, F., Altunkaynak, A. (2017). Comparison of numerical and experimental analyses for optimizing the geometry of OWC systems. Ocean Engineering, 130: 1024. http://doi.org/10.1016/j.oceaneng.2016.11.054

[22] Costi, J., Marques, W.C., Kirinus, E.P., Duarte, R.D.F., Arigony-Neto, J. (2018). Water level variability of the Mirim - São Gonçalo system, a large, subtropical, semienclosed coastal complex. Advances in Water Resources, 117: $75-86$. https://doi.org/10.1016/j.advwatres.2018.05.008

[23] Dimakopoulos, A., Cooker, M., Bruce, T. (2017). The influence of scale on the air flow and pressure in the modelling Water Column Wave Energy Converter. International Journal of Marine Energy, 19: 272-291. https://doi.org/10.1016/j.ijome.2017.08.004

[24] Çelik, A., Altunkaynak, A. (2019). Experimental investigations on the performance of a fixed-oscillating water column type wave energy converter. Energy, 188: 116071. https://doi.org/10.1016/j.energy.2019.116071

[25] Conde, J.M., Gato, L.M.C. (2008). Numerical study of the air-flow in an oscillating water column wave energy 
converter. Renewable Energy, 33: 2637-2644. http://dx.doi.org/10.1016/j.renene.2008.02.028

[26] Lisboa, R.C., Teixeira, P.R.F., Torres, F.R., Didier, E. (2018). Numerical evaluation of the power output of an oscillating water column wave energy converter installed in the southern Brazilian coast. Energy, 162: 1115-1124. https://doi.org/10.1016/j.energy.2018.08.079

[27] Elhanafi, A., Macfarlane, G., Fleming, A., Leong, Z. (2017). Experimental and numerical investigation on the hydrodynamic performance of a floating-moored oscillating water column wave energy converter. Applied Energy, 205: 369-390. http://doi.org/10.1016/j.apenergy.2017.07.138

[28] Bouali, B., Larbi, S. (2017). Sequential optimization and performance prediction of an oscillating water column wave energy converter. Ocean Engineering, 131: 162173. http://dx.doi.org/10.1016/j.oceaneng.2017.01.004

[29] Kharati-Koopaee, M., Fathi-Kelestani, A. (2020). Assessment of oscillating water column performance: Influence of wave steepness at various chamber lengths and bottom slopes. Renewable Energy, 147: 1595-1608. https://doi.org/10.1016/j.renene.2019.09.110

[30] He, F., Leng, J., Zhao, X. (2017). An experimental investigation into the wave power extraction of a floating box-type breakwater with dual pneumatic chambers. Applied Ocean Research, 67: 21-30. https://doi.org/10.1016/j.apor.2017.06.009

[31] Bejan, A. (2000). Shape and Structure, from Engineering to Nature. Cambridge University Press, New York, USA.

[32] Bejan, A., Lorente, A. (2008). Design with Constructal Theory. John Wiley \& Sons, Hoboken, New Jersey, USA

[33] Bejan, A. (2016). The Physics of Life: The Evolution of Everything. St. Martins Press, New York, USA.

[34] Dos Santos, E.D., Isoldi, L.A., Gomes, M.N., Rocha, L.A.O. (2017). The constructal design applied to renewable energy systems. In: Rincón-Mejía E, de las Heras A (eds.). Sustainable Energy Technologies. 1 Ed., Boca Raton: CRC Press - Taylor \& Francis Group, 6387. https://doi.org/10.1201/9781315269979

[35] Gomes, M.N., Lorenzini, G., Rocha, L.A.O., Dos Santos, E.D., Isoldi, L.A. (2018). Constructal Design applied to the geometric evaluation of an oscillating water column wave energy converter considering different real scale wave periods. Journal of Engineering Thermophysics, 27: 173-190. https://doi.org/10.1134/S1810232818020042

[36] Patankar, S.V. (1980). Numerical Heat Transfer and Fluid Flow. McGraw Hill, New York, USA.

[37] Versteeg, H.K., Malalasekera, W. (2007). An Introduction to Computational Fluid Dynamics. $2^{\text {nd }}$ Edition, Pearson, UK.

[38] Hirt, C.W., Nichols, B.D. (1981). Volume of fluid (VOF) method for the dynamics of free boundaries. Journal of Computational Physics, 39(1): 201-225. https://doi.org/10.1016/0021-9991(81)90145-5

[39] Schlichting, H. (1979). Boundary-Layer Theory. McGraw-Hill, New York, USA.

[40] Dean, R.G., Dalrymple, R.A. (1991). Water wave mechanic for engineers and scientists. Vol. 2: Advanced Series on Ocean Engineering. World Scientific Co. Pte. Ltd.

[41] FLUENT User's Guide, version 14.0. (2011). ANSYS Inc.

[42] Liu, Z., Hyun, B., Hong, K. (2011). Numerical study of air chamber for oscillating water column wave energy convertor. China Ocean Engineering, 25: 169-178. https://doi.org/10.1007/s13344-011-0015-8

\section{NOMENCLATURE}

$\begin{array}{ll}A_{1} & \text { area of the chamber, } \mathrm{m}^{2} \\ A_{2} & \text { area of the ramp, } \mathrm{m}^{2} \\ \vec{F} & \text { external body forces, } \mathrm{N} / \mathrm{m}^{3} \\ g & \text { gravity, } \mathrm{m} / \mathrm{s}^{2} \\ h & \text { water depth, } \mathrm{m} \\ H & \text { wave height, } \mathrm{m} \\ H_{1} & \text { height of the chamber, } \mathrm{m} \\ H_{2} & \text { height of the ramp, } \mathrm{m} \\ H_{3} & \text { submersion of the frontal wall of the } \\ & \text { chamber, } \mathrm{m} \\ H_{4} & \text { distance from the ramp surface to the frontal } \\ k & \text { wall of the chamber, } \mathrm{m} \\ L_{1} & \text { wave number, } 1 / \mathrm{m} \\ L_{2} & \text { length of the chamber, } \mathrm{m} \\ \dot{m} & \text { length of the ramp base, } \mathrm{m} \\ p & \text { mass flow rate, } \mathrm{kg} / \mathrm{s} \\ P & \text { pressure, N/m }{ }^{2} \\ t & \text { available power, } \mathrm{W} \\ T & \text { time, } \mathrm{s} \\ u & \text { wave period, } \mathrm{s} \\ \vec{v} & \text { velocity component in the } x \text {-direction, } \mathrm{m} / \mathrm{s} \\ x & \text { velocity vector of the flow, m/s } \\ w & \text { horizontal direction, } \mathrm{m} \\ z & \text { velocity component in the } z \text {-direction, } \mathrm{m} / \mathrm{s}\end{array}$

\section{Greek symbols}

$\begin{array}{ll}\alpha & \text { volume fraction, dimensionless } \\ \Delta t & \text { time-step, } \mathrm{s} \\ \Delta p & \text { pressure variation, } \mathrm{N} / \mathrm{m}^{2} \\ \eta & \text { free-surface elevation, } \mathrm{m} \\ \lambda & \text { wavelength, } \mathrm{m} \\ \mu & \text { fluid dynamic viscosity, } \mathrm{kg} /(\mathrm{m} \cdot \mathrm{s}) \\ \rho & \text { fluid density, } \mathrm{kg} / \mathrm{m}^{3} \\ \bar{\tau} & \text { deformation rate tensor, } \mathrm{N} / \mathrm{m}^{2} \\ \sigma & \text { wave frequency, } 1 / \mathrm{s}\end{array}$

\section{Subscripts}

$\begin{array}{ll}\mathrm{m} & \begin{array}{l}\text { once maximized } \\ \text { twice maximized } \\ \mathrm{mm}\end{array} \\ \mathrm{o} & \begin{array}{l}\text { once optimized } \\ \text { twice optimized }\end{array}\end{array}$

\section{Abbreviations}

$\begin{array}{ll}\text { DOF } & \text { Degree of Freedom } \\ \text { FVM } & \text { Finite Volume Method } \\ \text { NSE } & \text { Nash-Sutcliffe coefficient of efficiency } \\ \text { OWC } & \text { Oscillating Water Column } \\ \text { OWEC } & \text { Ocean Wave Energy Converters } \\ \text { PTO } & \text { Power Take Off } \\ \text { RMS } & \text { Root Mean Square } \\ \text { VOF } & \text { Volume of Fluid }\end{array}$

